\title{
Analisa dan Penanganan Terjadinya Penurunan Kevakuman pada Kondensor Utama Terhadap Kinerja Turbin Uap Di Kapal LNG
}

\author{
M. Ridwan ${ }^{1}$, Rosna Yuherlina ${ }^{2}$, Dimas Andika Putra ${ }^{3}$ \\ ${ }^{1,2,3}$ Prodi Teknika \\ Sekolah Tinggi Ilmu Pelayaran, Jakarta \\ Jl. Marunda Makmur No. 1 Cilincing, Jakarta Utara. Jakarta 14150
}

\begin{abstract}
Abstrak
Penggunaan turbin uap sangat diperlukan dalam penggerak utama kapal LNG. Tujuan penelitian ini adalah untuk mengetahui faktor-faktor apa yang mempengaruhi terjadinya penurunan kevakuman pada kondensor utama, dampak yang terjadi dengan adanya penurunan kevakuman pada kondensor utama dan upaya yang dapat dilakukan untuk mengatasi turunnya kevakuman di kondensor utama tersebut. Penelitian ini menggunakan metode kualitatif deskriptif yang bersifat eksplorasi untuk menggambarkan atas suatu fenomena. Fenomena yang diambil adalah tentang penurunan kevakuman pada main condenser yang berpengaruh besar terhadap kinerja dari main turbin. Kebocoran udara di dalam sistem, vacuum pump yang tidak normal, pengaruh tekanan dan temperature air pendingin kondensor, serta kesalahan pengoperasian adalah beberapa hal yang mempengaruhi penurunan kevakmuman tersebut. Penurunan kevakuman tersebut dapat menyebabkan sistem uap utama menjadi terganggu dan mengalami fail (auto slowdown) pada main turbin. Dan hal tersebut dapat diatasi dengan melakukan perawatan pada sistem dan meminimalisir kesalahan pengoperasian. Dari hasil penelitian disimpulkan bahwa penurunan kevakuman disebabkan oleh beberapa faktor diantaranya kebocoran udara ke dalam sistem melalui sambungan flans dan packing labyrinth, kinerja vacuum pump yang tidak optimal, turunnya tekanan air pendingin main condenser, naiknya suhu air pendingin yang dipengaruhi oleh faktor alam, dan kesalahan pengoperasian dalam menjalankan turbo generator.
\end{abstract}

Copyright $($ ) 2020, Prosiding Seminar Pelayaran dan Riset Terapan

Kata Kunci: penurunan, kevakuman, kondensor utama, turbin uap

Permalink/DOI : https://doi.org/10.36101/pcsa.v2i1.134

\section{PENDAHULAN}

Saat ini, kebutuhan terhadap bahan bakar minyak bumi terus meningkat sehingga bahan bakar minyak bumi merupakan jenis bahan bakar yang terbesar yang digunakan diseluruh dunia. Pemakaian bahan bakar minyak bumi diseluruh dunia menimbulkan suatu permasalahan terhadap kelangsungan hidup makhluk di bumi ini yaitu meningkatnya suhu bumi atau yang kita kenal dengan pemanasan global, hal ini disebabkan karena gas karbon yang berasal dari hasil sisa pembakaran bahan bakar yang berasal dari minyak bumi.

Untuk itu maka dicari suatu bahan bakar alternatif yang ramah terhadap lingkungan, salah satunya adalah bahan bakar yang berasal dari gas alam (Natural Gas). Disamping ramah terhadap lingkungan sumber bahan bakar gas alam ini juga mempunyai cadangan yang sangat banyak.

Untuk mendistribusikan bahan bakar gas alam ini ke seluruh dunia diperlukan suatu alat transportasi yang aman dan efisien, berupa kapal yang dibuat khusus agar mampu mengangkut muatan ini secara aman. Mengingat gas alam ini mempunyai sifat atau karakteristik yang khusus. Bagi negara Indonesia sejak ditemukannya sumber-sumber bahan bakar gas alam di Provinsi Nangroe Aceh Darussalam tepatnya di Arun dan Provinsi Kalimantan Timur yaitu di kota Bontang serta yang paling terbaru di Provinsi Papua tepatnya di Tangguh, merupakan salah satu negara terbesar pengekspor gas alam cair (Liquified Natural Gas), disingkat LNG.

Pada kapal-kapal pengangkut LNG (Liquified Natural Gas), sebagian kapal masih menggunakan turbin uap. Penggunaan turbin uap sebagai penggerak utama kapal karena berbagai faktor, salah satunya yaitu LNG dapat dimanfaatkan muatannya, LNG itu sendiri mudah menguap, daripada penguapan LNG tersebut dibuang ke atmosfer, maka lebih baik dimanfaatkan. Penguapan tersebut dibakar ke ketel induk yang dinamakan Boil Off Gas. 
Boil Off Gas ini baik digunakan sebagai bahan bakar ketel induk. Dengan Boil Off Gas ini pembakaran diketel akan semakin baik, uap yang dihasilkan juga akan maksimal. Ketel induk mempunyai peranan penting dikapal dengan tenaga penggerak turbin uap. Uap yang dihasilkan ketel induk digunakan untuk menggerakkan turbin sebagai penggerak utama kapal.

Selain ketel induk banyak instalasi lain yang menunjang kelancaran kinerja turbin uap. Salah satunya adalah kondensor utama. Diantara ketel uap, turbin uap, dan kondensor utama tidak dapat dipisahkan karena merupakan siklus terjadinya tenaga penggerak kapal.

Apabila pada salah satu terjadi masalah akan berakibat juga pada yang lain. Kondensor adalah sebuah pesawat yang berfungsi untuk merubah uap bekas menjadi air kondensat dengan cara kondensasi melalui proses pendinginan. Kondensor utama instalasi yang dipasang pada kapal dengan turbin uap sebagai penggerak utamanya, fungsinya yaitu mengodensasikan uap bekas dari turbin uap. Uap bekas yang sudah terkondensasi menjadi air akan disirkulasikan kembali sebagai air pengisi ketel.

Kondensor utama sebagai instalasi turbin uap harus setelah digunakan memutar sudu turbin sehingga tidak terjadi back pressure. Kondisi vacum berfungsi untuk menghisap uap bekas. Dengan kondisi vacum kondensor utama yang baik, akan membuat turbin uap beroperasi secara normal. Kondisi kevakuman di kondensor utama bisa saja menurun dikarenakan berbagai hal, sehingga mengakibatkan pengoperasian turbin uap menjadi terganggu, sehingga kevakuman perlu dijaga tetap baik.

Penelitian ini dilakukan karena banyaknya masalah-masalah yang timbul akibat kevakuman yang sering berkurang, sehingga hal ini dapat mempengaruhi kelancaran pengoperasian kapal karena pengaruh dari tidak maksimalnya turbin uap. Akibat umum yang ditimbulkan dari kurangnya kevakuman kondensor utama adalah kinerja ketel induk berkurang karena sirkulasi air pengisi ketel dari kondensor terhambat.

Upaya menjaga kevakuman pada kondensor utama sangat penting untuk dibahas, juga diperlukan perawatan yang benar dan teratur sehingga pada akhirnya dapat membatu kelancaran pengoperasian kapal serta meringankan tugas perwira mesin di atas kapal.

Dari penjelasan tersebut, dapat ditemukan masalah sebagai berikut:

1. Kebocoran udara di dalam sistem instalasi turbin uap.

2. Tidak optimalnya kinerja pompa vakum.

3. Penurunan tekanan air pendingin kondensor.
4. Naiknya suhu air pendingin kondensor.

5. Kesalahan pengoperasian saat menjalankan turbin generator

Berdasarkan uraian yang telah disampaikan dalam latar belakang, peneliti merumuskan permasalahan sebagai berikut:

1. Mengapa terjadi kebocoran udara di dalam sistem instalasi turbin uap?

2. Mengapa terjadi tidak optimalnya kinerja dari pompa vakum?

3. Mengapa terjadi penurunan tekanan air pendingin kondensor?

Kemudian tujuan dilaksanakannya penelitian ini yaitu:

1. Agar sistem instalasi turbin uap dapat bekerja dengan optimal.

2. Mempermudah dan memperlancar kerja terhadap masinis kapal dan pemilik kapal dalam upaya penanganan terjadinya vakum menurun pada kondensor yang dapat mengganggu kinerja turbin uap.

\section{METODE}

Metode Pendekatan yang digunakan dalam penelitian ini adalah metode pendekatan deskriptif kualitatif. Dalam memperoleh data peneliti menggunakan teknik pengumpulan data berupa observasi. Tempat penelitian ini dilaksanakan di atas kapal LNG/C Golar Mazo, milik perusahaan Faraway Maritime Shipping Company, Liberia adalah sebagai operator Golar Management (UK) Ltd, London. Dan management Golar Wilhelmsen Shipping Pte, Ltd sebagai manager, serta agen Indonesia PT Equinox Jakarta.

Adapun data kapal sebagai berikut:

$\begin{array}{ll}\text { Nama kapal } & : \text { LNG/C Golar Mazo } \\ \text { Nama panggilan } & : \text { ELX16 } \\ \text { Biro klasifikasi } & : \text { Lloyd Register of } \\ & \text { Shipping } \\ \text { Tahun pembuatan } & : \text { 2000 } \\ \text { Type kapal } & : \text { LNG Carrier (Liquified } \\ & \text { Natural Gas) } \\ \text { DWT } & : \text { 67060 ton } \\ \text { Mesin Induk } & : \text { MHI Type MS 32-2 } \\ \text { Jenis Mesin } & : \text { Turbin Uap } \\ \text { Putaran Mesin } & : \text { 80 RPM } \\ \text { Daya Mesin } & : 28.987 \text { HP }(21.320 \mathrm{KW})\end{array}$

\section{HASIL DAN PEMBAHASAN}

1. Kebocoran udara di dalam sistem instalasi turbin uap

Pada tanggal 31 Agustus 2017, ketika kapal dalam posisi stand - by engine untuk ketibaan di pelabuhan Yung-an, Taiwan ketika dalam proses anchorage ditemukan ketidak normalan pada kondensor mengalami penurunan vakum hingga $70 \%$ sedangkan untuk vakum tekanan normal -76 
cmHgVac (diatas90\%).

Kemudian dengan adanya masalah ini chief engineer memberi tugas kepada masinis tiga untuk mencari tahu permasalahan yang sedang terjadi ke lokasi kondensor berada. Ternyata terdapat kebocoran udara pada koneksi antara turbin utama dan kondensor utama pada sambungan pipa (flange), kebocoran udara luar yang masuk ke dalam sistem akan merusak tekanan vakum. Tekanan vakum akan menurun, titik didih zat cair akan naik dan proses kondensasipun akan bermasalah

2. Tidak optimalnya kinerja dari pompa vakum.

Tanggal 27 Oktober 2017 ketika kapal underway dari Bontang, Kalimantan Timur menuju Yung-an, Taiwan untuk melakukan proses pengiriman muatan ditemukan bahwa adanya alarm yang berbunyi di kamar mesin ketika para kru kamar mesin sedang melakukan kegiatan kerja harian, setelah Masinis 2 pergi untuk memeriksa jenis alarm apakah yang sedang berbunyi, dan ditemukan pemicu alarm yang berbunyi menurunnya vakum pada kondensor hingga 500 mmHg Vac sedangkan dalam keadaan normal yaitu $772 \mathrm{mmHg}$ Vac, masalah ini dapat mengakibatkan turbin uap slowdown bahkan bisa turbin uap trip.

Setelah dilakukannya analisa pada permasalahan tersebut, ditemukan penyebab dari kejadian ini adalah kurang optimalnya kinerja dari pompa vakum nomer 2 , dengan segera masinis tiga menyalakan pompa vakum nomer 1 untuk menggantikan pompa yang mengalami gangguan.

3. Penurunan tekanan air pendingin kondensor.

Pada tanggal 15 maret 2018 kapal LNG/C GOLAR MAZO melakukan anchorage di pelabuhan Bontang Kalimantan Timur, engineer mulai dari masinis 1 , masinis 3 , electrician serta oiler sedang bekerja sesuai dengan pekerjaan masing-masing. Sekitar pukul 14:00 WIB, tibatiba alarm high temperature pada kondensor utama berbunyi, masinis 1 yang sedang berada di ECR (Engine Control Room) langsung mematikan bunyi alarm dan mengecek ke lokasi untuk melihat temperature pada kondensor bantu,dan benar saja, temperature pada kondensor bantu saat itu menunjukan angka $1700 \mathrm{~F}$, sedangkan temperature normal pada kondensor antara $1100 \mathrm{~F}$ sampai dengan $1200 \mathrm{~F}$.

Masinis 3 langsung menyusul masinis $1 \mathrm{ke}$ lokasi kondensor, sekitar 2 menit kemudian alarm vacuum low pressure berbunyi, vakum pada kondensor normalnya yaitu $772 \mathrm{mmHg}$ vacuum pada temperature air pendingin $27^{\circ} \mathrm{C}$, sedangkan pada saat alarm vakum menunjukan angka 500 $\mathrm{mmHg}$ vacuum. Pada saat pemeriksaan ditemukan adanya tekanan air pendingin yang turun sehingga mengakibatkan kekurangan air pendingin pada kondensor utama, Apabila jumlah air tidak sebanding dengan uap bekas yang masuk kondensor maka banyak uap bekas yang tidak terkondensasi itulah yang menyebabkan penurunan vakum.

Dalam analisa hasil penelitian dan pembahasan ini penulis mengemukakan tentang faktor-faktor yang menjadi masalah terhadap menurunnya kevakuman pada kondensor utama dan pengaruh yang ditimbulkan akibat dari masalah terhadap kinerja turbin uap serta upaya yang dilakukan untuk mengatasi permasalahan tersebut. Vakum pada kondensor utama dapat berubah-ubah. Vakum dapat tercapai tergantung pada faktor-faktor seperti temperatur air pendingin, tekanan air pendingin, besarnya koefisien transmisi kalor dan kadar kebocoran udara.

Uap yang dimasukkan ke dalam kondensor utama adalah uap bekas dari turbin uap, uap bekas dari turbo generator dan dari katup-katup cerat. Uap menyerahkan panas pada air pendingin yang masuk dengan suhu tertentu dan keluar dengan suhu yang lebih tinggi dari suhu sebelum air pendingin masuk. Jumlah air pendingin sangat dibutuhkan untuk menkondensasikan sejumlah uap bekas. Jumlah normal air pendingin yang masuk adalah $12000 \mathrm{~m} 3$ per jam, dan suhu air pendingin ditentukan oleh air pendingin yang tersedia. Untuk keperluan kapal ialah air laut di luar lambung yang suhunya sangat bervariasi tergantung dari posisi kapal berada. Suhu air laut ini berkisar $0^{\circ} \mathrm{C}$ (di daerah kutub) sampai sekitar $30^{\circ} \mathrm{C}$ (di daerah tropis). Suhu air pendingin menentukan proses kondensasi berjalan dengan baik, dengan pengecualian faktor-faktor kebocoran udara dan kontaminasi serta tekanan dalam kondensor dalam keadaan baik.

Ada hubungan antara jumlah air pendingin, suhu air pendingin dan vakum yang tercapai dalam kondensor.

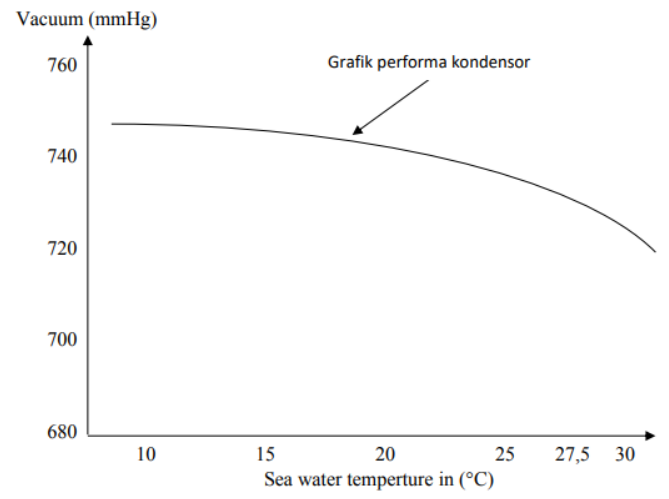

Gambar 1. Main Condenser Vacuum Performance Curve (LNG/C Golar Mazo instruction manual book) 
Pada gambar 1 terlihat bahwa Apabila Main Condenser Vacuum Performance Curve semakin tinggi nilai vakumnya maka suhu air pendingin semakin rendah kemudian proses kondensasinya akan semakin tinggi. Apabila terjadi penurunan nilai vakum dan naiknya suhu air pendingin menyebabkan proses kondensasinya menurun.

Apabila terdapat vakum yang buruk dalam kondensor maka faktor-faktor berikut yang menjadi penyebabnya:

a. Kebocoran udara ke dalam sistem instalasi turbin uap

Faktor ini yang sering penulis alami pada saat menjalani praktek laut. Apabila terjadi kebocoran udara ke dalam sistem akan membuat vakum kondensor menurun. Tekanan udara luar adalah $1 \mathrm{~atm}$, sedangkan untuk vakum tekanan normalnya $-76 \mathrm{cmHgVac}$ (diatas $90 \%$ ). Pada saat terjadi udara masuk tekanan vakum akan turun mencapai $70 \%$.

Kebocoran udara luar yang masuk ke dalam sistem akan merusak tekanan vakum. Tekanan vakum akan menurun, titik didih zat cair akan naik dan proses kondensasipun akan bermasalah. Uap bekas yang dialirkan tidak seimbang dengan kondensasi yang terjadi. Kebocoran udara masuk ke dalam sistem terjadi karena beberapa penyebab, yaitu :

1) Kebocoran udara pada koneksi antara turbin utama dan kondensor utama

Pipa yang berhubungan dengan turbin uap maupun kondensor utama salalu ada sambungan pipa (flange). Kadang kala sambungan pipa tersebut terdapat keregangan yang diakibatkan oleh getaran (vibration) dan umur pemakaian sehingga mengakibatkan packing rusak dan kendornya baut-baut pengikat, dampak yang terjadi adalah udara luar masuk ke dalam sistem sehingga kevakuman yang dibentuk sulit tercapai.

Rusaknya packing juga disebabkan karena usia dari packing itu sendiri yang sudah lama. Walaupun packing tersebut terbuat dari bahan bagus tetap dapat rusak jika sudah lama terpakai.

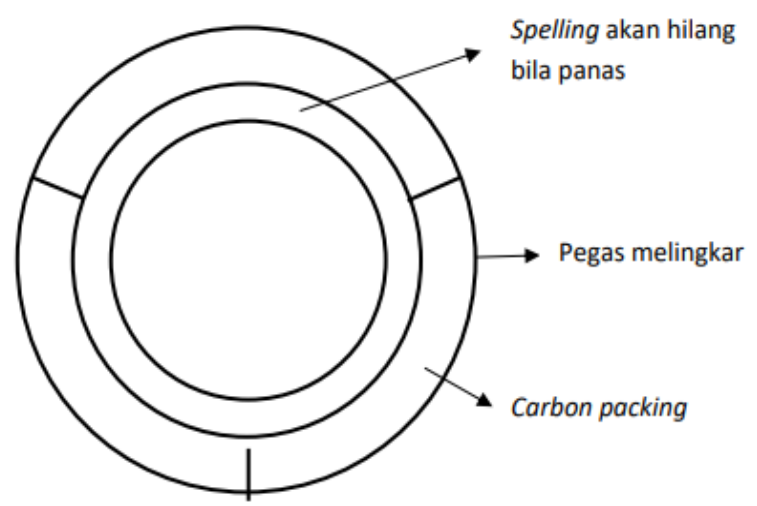

Gambar 2. Steam Packing (LNG/C Golar Mazo
Intruction Manual Book)

Pada Gambar 2 Steam Packing (LNG/C Golar Mazo Intruction Manual Book) digambarkan tentang desain dari steam packing. Bahan packing berbentuk potongan cincin-cincin terbuat dari campuran zat arang dan grafit.

Cincin terdiri dari beberapa bagian, umumnya terdapat 3 bagian dengan penampang persegi. Tiap bagian menyentuh satu sama lain secara tepat dan rapat. Ketiga bagian dijadikan satu oleh pegas pelat, sedang pelat-pelat ini ditarik oleh sebuah pegas spiral. Sifat dari karbon tersebut yaitu lunak dan bahan suhu tinggi. Tapi tidak menutup kemungkinan packing tersebut rusak. Apabila hal tersebut sampai terjadi maka akan timbul kebocoran dari sela-sela packing yang rusak.

2) Kebocoran udara karena gland steam packing labyrinth

Gland steam packing labyrinth merupakan uap dengan tekanan yang cukup rendah yaitu tekanan diatas $1 \mathrm{~atm}$, dalam hal ini menggunakan 0,17 MPa steam line. Pada saat melakukan pengamatan terjadi penurunan tekanan dari gland steam packing labyrinth, tekanan dibawah 0,17 $\mathrm{MPa}$ membuat vakum pada kondensor menurun. Uap ini dimasukkan ke dalam ujung-ujung poros turbin pada bagian packing labirin, yang berfungsi mencegah adanya udara luar (tekanan $1 \mathrm{~atm}$ ) yang masuk ke dalam turbin saat startup dan saat LP (Low Pressure) ataupun HP (High Pressure) turbine sedang tidak digunakan, dimana udara tersebut dapat mengurangi kevakuman di dalam main condenser.

Tidak normalnya dikarenakan jumlah uap kurang terpenuhi, gland steam packing alarm PAL : 4,9 KPa dan PAH : $34 \mathrm{KPa}$, pada hal ini gland steam packing pressure diatur pada controller 10 $\mathrm{KPa}$ untuk menghindari kenaikan dan penurunan yang terlalu signifikan sesuai dengan instruction manual book untuk kontrol gland steam packing labyrinth.

b. Tidak optimalnya kinrja dari pompa vakum

Pompa vakum merupakan bagian yang sangat penting pada sistem. Pompa vakum berfungsi untuk menghisap dan mengeluarkan udara yang terdapat di dalam kondensor utama. Pompa vakum kerjanya optimal jika :

- Putaran pompa normal : $1.750 \mathrm{Rpm}$

- Vakum pada kondensor : > $90 \%$

- Arus pada motor : 50 Ampere

Saluran isap pompa vakum terdapat pada kondensor utama bagian atas. Peranannya sangat vital dalam menjaga kevakuman agar tetap baik. Karena begitupentingnya terdapat dua pompa vakum di kapal. Satu pompa digunakan seharihari dan yang lainnya sebagai cadangan dalam 
keadaan standby. Penggunaan pompa secara bergantian sesuai running hours dan maintenance scedule. Ini bertujuan agar pompa berjalan secara normal, apabila terdapat masalah pada pompa yang satu maka dapat menggunakan pompa yang kedua. Ada kalanya pompa digunakan secara bersamaan yaitu pada saat vakum kondensor utama menurun secara drastis.

Untuk mencegah agar vakum tidak jatuh maka kedua pompa dijalankan secara bersamaan sambil mencari masalah yang terjadi. Pompa vakum beroperasi secara terus-menerus, baik turbin uap beroperasi maupun dalam kondisi turning gear, kecuali jika turbin dalam keadaan shut down. Hal ini bertujuan untuk menghisap udara dan uap bekas yang tidak bisa diuapkan di dalam kondensor utama sehingga di dapat keadaan vakum di kondensor utama.

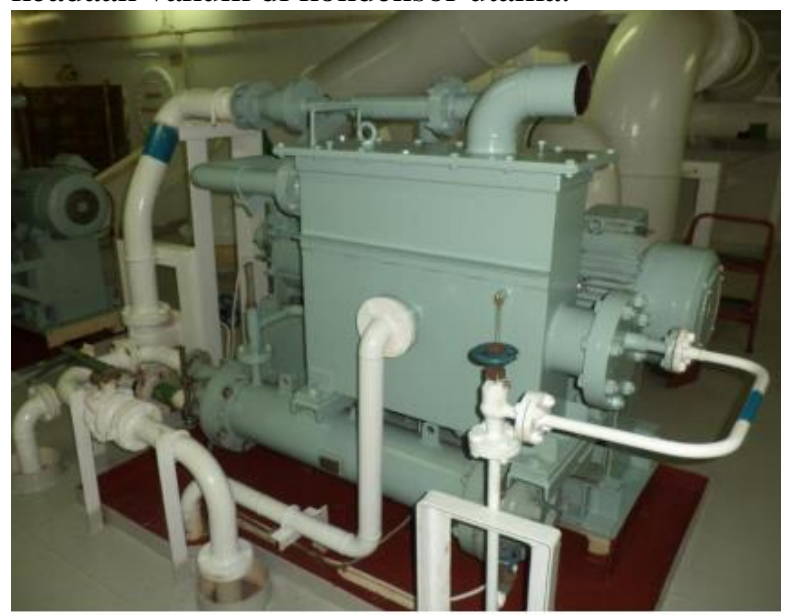

Gambar 3. Vacuum pump (LNG/C Golar Mazo document)

Pada saat penelitian, kejadian tidak optimalnya pompa vakum disebabkan oleh:

1) Kebocoran udara ke dalam sistem pada saluran isap pompa

Pada saluran isap terdapat sambungan yang menghubungkan antar bagian pipa sepanjang saluran isap pompa. Kerenggangan pada sambungan pipa ini membuat rongga untuk udara masuk ke dalam sistem. Pompa tidak menghisap dari kondensor melainkan menghisap udara luar yang masuk melalui rongga kebocoran tersebut, dan membuat kevakuman di kondensor tidak tercapai.

2) Runner dan casing cover terjadi kontak satu sama lain (rpm abnormal)

Terlalu longgar maupun terlalu sempit clearance dari runner dan casing cover membuat pompa vakum mengalami gangguan dalam operasinya. Terlalu rapat mengakibatkan terjadinya kontak antara runner dan casing cover. Jika dibiarkan hal tersebut terjadi maka dapat merusak kedua bagian mesin tersebut.

Indikasi terjadinya kontak antara runner dengan casing cover yaitu:

a) Terjadi getaran yang tidak normal

Pompa vakum akan menimbulkan getaran jika dijalankan. Getaran ini memang normal terjadi karena pompa berputar dengan kecepatan tinggi. Getaran terjadi karena ada gesekan antara dua buah permukaan dan gesekan yang terjadi antara runner dan casing cover membuat getaran yang tidak normal pada pompa. Getaran tersebut yang kemudian diikuti dengan panas. Pengecekan getaran dilakukan dengan mengambil sebuah benda logam padat yang cukup panjang kemudian salah satu bagian ujung logam tersebut ditempelkan pada casing pompa dan ujung yang lain ditempelkan ke telinga pengecek. Jika terjadi getaran yang tidak normal akan terdengar dengan jelas.

b) Casing panas setelah pompa mulai berjalan

Pada keadaan normal tidak terjadi panas yang berlebih pada bagian casing pompa. Panas yang terjadi karena adanya gesekan tersebut. Untuk mengetahui panas atau tidaknya dapat dicek secara langsung pada bagian pompa tersebut dengan menyentuh bagian casing cover.

Jika terasa panas yang berlebih artinya terjadi ketidak normalan pada bagian bagian pompa tersebut.

c) Pipa air ejector tersumbat

Tersumbatnya aliran udara ini akan menghambat proses pemvakuman kondensor. Tersumbatnya pipa air ejector dikarenakan endapanendapan kotoran dari uap bekas yang mengerak pada bagian dalam pipa.

d) Saluran isap pompa vakum tersumbat

Hambatan ini adalah pada saluran isap pompa vakum yang terletak di dalam kondensor bagian atas. Sama halnya dengan tersumbatnya pipa air ejector, sumbatan pada saluran isap ini dikarenakan endapanendapan yang mengerak pada dinding bagian dalam saluran isap pompa vakum.

c. Penurunan tekanan air pendingin kondensor

Uap bekas yang mengalir ke kondensor didinginkan dengan air pendingin yaitu air laut. Untuk mendinginkan uap bekas tersebut dibutuhkan jumlah air yang cukup.

Jumlah air tercukupi jika tekanan air lautnya sesuai tekanan normalnya, yaitu :

- Tekanan air pendingin (pompa dan scoop): 1 $\mathrm{kg} / \mathrm{cm}^{2}$

- Jumlah air pendingin : $12.000 \mathrm{~m}^{3} / \mathrm{jam}$

Untuk mengetahui tekanan air pendingin tersebut dapat dicek pada manometernya. Apabila jumlah air tidak sebanding dengan uap bekas yang masuk kondensor maka banyak uap bekas yang tidak terkondensasi sehingga menyebabkan vakum menurun dan tekanan di dalam kondensor 
bertambah. Pada saat pengamatan ditemukan adanya tekanan air pendingin yang turun sehingga mengakibatkan kekurangan air pendingin, hal ini dapat disebabkan oleh beberapa hal, antara lain :

1) Tersumbatnya sea chest

Sistem pendingin kondensor menggunakan dua cara, pertama dengan menggunakan circulating pump dan yang kedua menggunakan scoop. Scoop digunakan pada saat kapal dengan kecepatan tinggi. Air laut secara langsung masuk ke dalam kodensor karena isapan scoop tersebut. Sedangkan pada saat kapal dalam keadaan kecepatan rendah pendinginan menggunakan circulating pump.

Pada kecepatan rendah tidak bisa menggunakan scoop karena tekanan air pendingin tidak dapat tercapai. Air pendingin masuk melalui lubang sea chest, oleh karena itu jika sea chest tersumbat maka isapan circulating pump tidak maksimal dan jumlah air pendingin yang didistribusikan juga berkurang.

Terhambatnya aliran ini disebabkan karena adanya sampah laut yang menyumbat lubang air masuk pada sea chest.

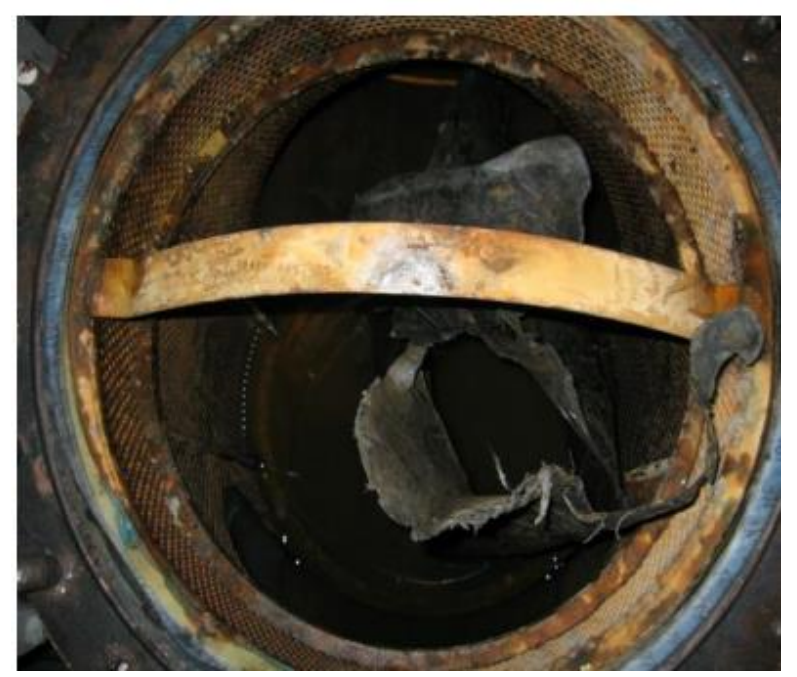

Gambar 4. Vacuum pump (LNG/C Golar Mazo document)

2) Sumbatan pada pipa-pipa saluran kondensor

Pipa-pipa air pendingin kondensor dapat tersumbat oleh kotoran-kotoran yang terbawa aliran air. Kotoran-kotoran yang mengendap didalam pipa-pipa ini menghambat aliran air pendingin ke kondensor, sehingga jumlah air pendingin akan berkurang.

Kotornya air laut disuatu perairan tertentu membawa dampak yang buruk pada kondensor utama. Kotor atau tersumbatnya pipa-pipa kondensor membuat jumlah aliran air pendingin tidak tecapai walaupun tekanan pompanya sudah sesuai. Kotoran-kotoran ini juga dapat berdampak korosi atau erosi pada bagian-bagian pipa. Erosi disisi air pendingin terjadi disisi air masuk pipa karena kisaran air, terutama pada kecepatan tinggi dan hambatan yang terjadi pada permukaan kondensor utama.

3) Terhambatnya saluran scoop

Pada saat dry dock ditemukan masalah pada katup inlet scoop. Scoop adalah saluran air laut yang langsung digunakan untuk mendinginkan kondensor utama. Scoop digunakan pada saat putaran poros mesin induk diatas $64 \mathrm{rpm}$.

Ketika katup masuk scoop terbuka, circulating pump akan mati secara otomatis. Saat putaran poros utama dibawah $64 \mathrm{rpm}$, katup scoop akan menutup dan circulating pump akan berjalan secara otomatis. Karena keduanya telah diatur secara otomatis apabila terjadi gangguan akan menjadi masalah yang berdampak penting pada jalannya mesin induk. Masalah lain yang terjadi pada scoop adalah ketika putaran poros sudah pada putaran untuk membuka katup scoop tetapi katup scoop tidak membuka sepenuhnya sehingga aliran air laut menjadi berkurang.

4) Tidak optimalnya kerja dari circulating pump

Dibutuhkan tekanan air pendingin yang cukup untuk mendinginkan uap bekas di kondensor utama agar uap bekas dapat terkondensasi dengan tepat. Tekanan ini dihasilkan dari kerja main circulating pump. Apabila tekanan air pendingin berkurang dapat dikarenakan terjadi masalah pada pompa sehingga pompa tidak dapat bekerja dengan optimal. Pada tekanan yang normal 1 $\mathrm{kg} / \mathrm{cm}^{2}$ dapat memompa air laut sebesar $2500 \mathrm{~m}^{3}$ per jam. Faktor-faktor yang menjadi kendala tidak optimalnya kerja pompa antara lain :

a) Kebocoran pada saluran tekan pompa

Kebocoran yang terjadi pada bagian saluran tekan membuat tekanan pompa berkurang. Kebocoran sering terjadi pada sambungan pipa rubber gasket yang telah rusak. Jika terjadi kebocoran air akan keluar dari sistem yang dapat menyebabkan banjir pada tank top bila dibiarkan.

b) Udara masuk ke dalam pompa

Udara yang masuk kedalam pompa membuat pompa hanya menghisap udara, jumlah air berkurang karena tidak ada isapan air.

c) Kerusakan pada bagian pompa

Kerusakan pada bagian pompa seperti rusaknya impeller atau pada mechanical seal akan membuat pompa bekerja tidak optimal.

Dari permasalahan yang penulis angkat mengenai penurunan kevakuman pada kondensor utama terhadap kinerja turbin uap akbiat dari kebocoran udara di dalam sistem, tidak optimalnya kinerja pompa vakum, dan penurunan tekanan air pendingin kondensor.

Adapun cara atau langkah yang ditempuh untuk mempertahankan kevakuman yang baik antara lain :

1. Kebocoran udara yang masuk ke dalam sistem 
solusinya adalah:

a) Mengusahakan agar tidak ada kebocoran udara yang masuk ke dalam sistem

Kevakuman udara sangat berpengaruh sekali terhadap kinerja kondensor sehingga bila terjadi kebocoran udara yang masuk ke dalam system, maka kondensor tidak mungkin akan bekerja secara optimal, sehingga diperlukan perbaikan/ perawatan pada sambungan pipa-pipa atau katupkatup yang berhubungan dengan kondensor utama dengan cara dilakukan pengecekan satu persatu pada sambungan pipa-pipa. Pengecekan dilakukan dengan melakukan pengencangan pada baut-baut sambungan pipa. Apabila pada bagian yang sudah dikencangkan ternyata tidak berdampak apapun pada kevakuman, maka dilanjutkan dengan melihat kondisi dari sambungan pipa tersebut (flange).

Karena walaupun packing tersebut terbuat dari bahan yang bagus tetap dapat rusak jika sudah lama terpakai, dengan menganti packing steam yang lama dengan yang baru kebocoran udara yang masuk ke dalam system dapat ditangani. Untuk mengusahakan kondisi dari sambungan pipa-pipa atau katupkatup yang berhubungan dengan main condenser agar tidak mengalami kebocoran perlu adanya pemeriksaan setiap saat bila mengetahui adanya kebocoran maka segera lakukan perbaikan

b) Usahakan gland steam packing labyrinth tetap normal

Gland steam packing labyrinth didapat dari uap utama yang diturunkan tekanannya. Alat penurun tekanan uap (reducer) harus berfungsi dengan semestinya untuk mencapai tekanan yang ditentukan. Untuk mendapatkan gland steam packing labyrinth yang tetap normal yaitu dengan melakukan perawatan pada gland steam exhaust fan dengan melakukan pembersihan secara berkala agar exhaust fan tetap bekerja dengan baik. Serta usahakan tekanan uap yang digunakan untuk gland steam packing labyrinth tidak dibawah batas tekanan yang ditentukan.

2. Tidak optimalnya kinerja dari pompa vakum

Untuk mendapatkan kerja dari pompa vakum yang baik didapat melalui perawatan secara rutin sesuai dengan buku manualnya. Lakukan pengecekan pada level air dalam tangki dan jika terjadi kenaikan level maka lakukan penceratan sampai batas level yang normal. Lakukan pergantian kerja dari pompa satu bulan sekali agar didapat running hours yang sama antara kedua pompa. Selain mengecek secara fisik pompa vakum, perlu dilakukan juga pengecekan terhadap suku cadang dari pompa vakum tersebut. Jangan sampai pada saat dibutuhkan suku cadangnya tidak tersedia. Apabila ditemukan ketidak ketersediaan suku cadang tersebut, segera mengirimkan permintaan suku cadang. Berikut ini langkah-langkah dalam perawatan pompa vakum :

i. Perawatan

a) Membersihkan saringan pada pipa ejector

b) Memberikan grease pada bagian yang memerlukan grease

c) Membersihkan cooler pompa

d) Mencerat air tangki pompa agar tidak berlebihan

ii. Pemeriksaan

a) Memeriksa sambungan dari kebocoran udara

b) Memeriksa getaran pompa

c) Memeriksa putaran motor

iii. Perbaikan

a) Mengganti packing yang sudah rusak

b) Penggantian bearing yang sudah rusak

c) Mengganti saringan

d) Mengganti semua bagian yang perlu diganti pada saat overhaul pompa

3. Penurunan tekanan air pendingin kondensor

Turunnya tekanan air pendingin membuat kondensor kekurangan jumlah air pendingin, hal ini terjadi karena beberapa faktor. Untuk mengusahakan tidak terjadi kekurangan jumlah air pendingin yaitu dengan cara :

a) Melakukan perawatan main circulating pump

Perawatan pada main circulating pump dilakukan sesuai dengan buku manualnya. Bekerjanya dengan baik pesawat chloropac dapat mencegah timbulnya carryover yang dapat menyebabkan pipa-pipa main condenser tersumbat. Untuk melakukan pembersihan sea chest dilakukan pada saat dry docking. Langkahlangkah pencegahan kerusakan pada circulating pump yaitu :

i. Perawatan

a) Pembersihan saringan air laut masuk

b) Perawatan pada MGPS (Marine Growth Preventing System)

c) Pemberian grease pada bearing

d) Membersihkan selang pendingin mechanical seal

ii. Pemeriksaan

a) Pengecekan adanya kebocoran

b) Pengecekan tekanan pada manometer

c) Pemeriksaan putaran motor

d) Pemeriksaan visual pada seluruh bagian pompa

iii. Perbaikan

a) Mengganti packing sambungan pipa yang telah rusak

b) Mengganti mechanical seal yang bocor

c) Mengganti bagian pompa yang rusak saat overhaul

b). Melakukan pembersihan pipa-pipa main 
condenser

Pembersihan pipa-pipa di main condenser dilakukan sesuai buku manualnya, atau bila terjadi perbedaan tekanan maupun temperature yang terlalu sedikit. Pembersihan pipa-pipa di main condenser dapat dilakukan pada saat kapal berhenti, sehingga main turbine tidak bekerja dan kapal tidak sedang bongkar muat. Pembersihan ini dilakukan pada saat kapal dry dock. Apabila diketahui adanya pipa pendingin yang bocor, maka harus diambil tindakan perbaikan yaitu dengan cara menyumbat saluran masuk dan keluar dari pipa pendingin agar air laut tidak bercampur dengan air kondensat.

c). Melakukan pengecekan sistem control otomatis pada katup scoop

Apabila terjadi masalah pada katup scoop hanya bisa diperbaiki pada saat dry dock karena letak scoop yang berada dibawah dan terendam air laut. Untuk mencegah terjadinya kerusakan harus selalu dilakukan pengecekan secara terjadwal. Pengecekan katup ini dilakukan pada saat katup tidak sedang dioperasikan.

Dari alternatif pemecahan masalah tersebut yang telah di bahas, maka dapat dievaluasikan pemecahan masalah sebagai berikut:

1. Kebocoran udara di dalam system instalasi turbin uap

Penyebab dari permasalahan ini berkaitan dengan kondisi dari sambungan pipa-pipa atau katup-katup yang berhubungan dengan kondensor utama, maka dapat disimpulkan evaluasi dari pemecahan masalah yang telah disarankan sebagai berikut :

a. Kurangnya dalam melakukan perwatan serta pemeliharaan kondisi dari sambungan pipapipa atau katup-katup yang terhubung dengan main kondensor dapat berdampak negatif terhadap kevakuman pada kondensor utama seperti yang telah di jelaskan pada bagian sebelumnya, sehingga setiap jenis perawatan harus di lakukan dengan baik dan benar serta tepat waktu sesuai dengan PMS yang berlaku di atas kapal LNG/C GOLAR MAZO.

b. Tidak sempurnanya kondisi gland steam packing labyrinth. Pada hasil evaluasi maka diperoleh penanggulangannya dengan cara melakukan rencana perawatan yang terencana sesuai dengan buku panduan atau planned maintenance system yang telah di tetapkan dan di sarankan oleh biro klasifikasi kapal. Perawatan ini dapat di tindak lanjuti dengan cara pemeliharaan gland steam exhaust fun. Sangat penting untuk menjaga kevakuman pada kondensor utama dengan kondisi gland steam packing labyrinth tetap normal, dengan perawatan gland steam exhaust fun yang rutin dan berkelanjutan sesuai dengan jam kerja yang telah di tentukan dalam buku manual dan PMS yang berlaku. Agar dilakukan dengan penuh disiplin dan tanggung jawab oleh para masinis maupun crew engine di kapal sesuai dengan jam kerja (running hours) yang telah ditetapkan, Semuanya itu dilakukan agar dapat memperkecil kerusakan dan dapat berkerja dengann normal.

2. Tidak optimalnya kinerja dari pompa vakum Untuk mengatasi permasalahan tentang perawatan terhadap pompa vakum yang kurang makasimal berdasarkan alternatif pemecahan masalah di atas, maka dapat ditemukan evaluasi pemecahan masalah sebagai berikut :

a. Melaksanakan metode perawatan yang tepat dan sesuai dengan buku petunjuk dari pabrikan asal pompa vakum. Metode perawatan tersebut harus dilakukan secara terencana dan selalu dicatat agar dapat diketahui kondisi dari pompa vakum sehingga dapat menjaga kevakuman pada kondensor utama.

b. Melakukan penggantian suku cadang yang rusak maupun yang sudah akan melewati batas jam kerjanya dengan suku cadang asli dari pabrikan asal pompa vakum. Setiap penggunaan suku cadang harus di catat jam kerjanya, agar dapat diketahui kondisi dan dapat diganti sebelum melewati jam kerjanya dari suku cadang tersebut menurut buku petunjuk. Hal ini akan menyebabkan semua kompenen pada pompa vakum bekerja dengan maksimal. Kedua pemecahan masalah di atas tidak menjamin penuh atas masalah yang ada pada pompa vakum, akan tetapi dapat menjaga kondisi komponen pompa vakum dalam bekerja. Dampak dari pemecahan masalah di atas akan meningkatkan kemampuan dalam menjaga kondisi vakum pada kondensor utama dan menghasilkan kinerja yang maksimal

3. Penurunan tekanan air pendingin kondensor Solusi yang disarankan yaitu:

a. Melakukan perawatan berencana pada main circulating pump

Evaluasi terhadap perawatan berencana pada main circulating pump dapat menjaga dalam menghasilkan volume dan tekanan air laut sebagai media pendingin pada kondensor dan menjadikan kinerja dari main circulating pump menjadi lebih baik. Dengan memeriksa dan melakukan perawatan kita dapat menjaga performa dan kualitas dari pompa tersebut. Dan dalam melakukan perawatan kita dapat mengikuti 
langkah-langkah prosedur yang baik yang mana dapat kita lihat pada buku manual pada main circulating pump, agar menghasilkan perawatan yang maksimal.

Kekurangan dari alternatif pemecahan masalah ini adalah :

1) Jadwal pelayaran yang cukup padat yang mana proses perawatan tidak dapat dilaksanakan dengan baik.

2) Tidak adanya spare parts yang standby sehingga sewatu-waktu apabila dibutuhkan pergantian dapat langsung digantikan.

b. Melakukan pembersihan pipa-pipa kondensor utama

Evaluasi terhadap perawatan berencana pada kondensor sistem dapat mengakibatkan keleluasaan pada air laut untuk melewati sistem ini dan menjadikan kinerja dari kondensor menjadi lebih baik, dan mencegah terjadinya proses korosi, yang dapat merugikan perusahaan akibat terjadinya korosi dan mengakibatkan proses kondensasi yang terhambat karena banyak terdapat scalescale pada bagian permukaan pipa kondensor, material menjadi tidak bertahan lama.

Sesuai dengan PMS (Plan Maintenance Schedule) pada kapal LNG/C GOLAR MAZO. Dengan memeriksa dan melakukan perawatan kita dapat menjaga performa dan kualitas dari sistem itu sendiri. Dan dalam melakukan perawatan kita dapat mengikuti langkah-langkah prosedur yang baik yang mana dapat kita lihat pada buku manual, agar menghasilkan perawatan yang maksimal. Kekurangan dari pemecahan masalah ini hanya dapat dilakukan pada saat kapal dalam tidak bekerja dan dilakukan plan-down turbin atau saat drydock dilakukan.

\section{KESIMPULAN}

Setelah peneliti menguraikan beberapa permasalahan yang muncul serta pembahasan, maka dapat disimpulkan sebagai berikut:

1. Kebocoran udara didalam sistem instalasi turbin uap disebabkan oleh prosedur perawatan dan penanganan terhadap setiap sambungan sistem instalasi turbin uap kurang maksimal sehingga berdampak kebocoran udara didalam sistem isntalasi turbin uap adalah penyebab turunnya kevakuman di dalam kondensor utama yang dapat mempengaruhi kinerja dari turbin uap sebagai penggerak utama kapal.

2. Tidak optimalnya kinerja dari pompa vakum disebabkan oleh tidak terencana sistem perawatan yang dikerjakan serta tidak sesuai dengan buku petunjuk manual dari pabrikan asal, maka kinerja dari pompa vakum akan selalu dalam keadaan yang kurang maksimal dalam menjaga kevakuman pada kondensor.
3. Penurunan tekanan air pendingin kondensor disebabkan oleh perawatan dan pengoperasian main circulating pump yang tidak tepat dan tidak mengikuti prosedur yang tertera dalam instruction manual book.

Sehubung dengan permasalahan dibagian sebelumnya, penulis memberikan beberapa saran sebagai pemecahan masalah-masalah yang telah terjadi, diantaranya sebagai berikut:

1. Perawatan pada permesinan dilakukan sesuai dengan instruction manual book dan work order dari Chief Engineer maupun dari perusahaan untuk memperkecil resiko kerusakan permesinan. Untuk itu, hal-hal yang perlu diperhatikan pada perawatan kompenenkompenen setiap sambungan sistem instalasi turbin uap adalah :

a. Agar perawatan setiap komponen sesuai dengan jam kerja dari setiap bagian suku cadang tersebut dengan beracuan kepada buku manual.

b. Prosedur perawatan \& perbaikan harus sesuai dengan buku manual guna menghindari timbulnya permasalahanpermasalahan lain dikemudian hari.

2. Tidak optimalnya kinerja dari pompa vakum

Dalam melakukan perawatan terhadap pompa vakum harus sesuai dengan prosedur yang ada pada instruction manual book dan dilakukan dengan maksimal guna mencapai tujuan dan hasil yang sesuai dengan harapan. Sehingga, kinerja dari seluruh kompenen selalu dalam keadaan baik dan dapat mendukung kinerja dari kondensor selalu dalam keadaan siap untuk dioperasikan dan menghasilkan kinerja yang maksimal guna mendukung kegiatan pengoperasian kapal. Dan juga dilakukan pemeriksaan rutin terhadap pompa vakum sesuai dengan PMS yang berlaku.

3. Penurunan tekanan air pendingin kondensor

Pastikan setiap perawatan dan pengoperasian pada main circulating pump dilakukan sesuai dengan PMS yang berlaku dan mengikuti prosedur sesuai dengan instruction manual book serta dilakukan oleh tenaga yang kompeten, untuk mencegah penurunan tekanan air pendingin pada kondensor dan juga timbulnya permasalahan lain dikemudian hari yang dapat menyebabkan berbagai kerugian. Meningkatkan kualitas sumber daya manusia sebagai operator kapal dengan memberikan pelatihan sebelum memasuki kerja nyata diatas kapal dan mengoptimalkan familiarisasi kerja saat memulai lingkungan kerja yang baru untuk menghindari kesalahan pengoperasian atau human error. 


\section{DAFTAR PUSTAKA}

[1] Fox, W.J. \& McBirnie, S.C. (1970). Marine Steam Engines and Turbines. London: NewnesButterWorths

[2] Marcos, Ferdinand G. (1933). Modern Marine Engineers Handbook. Manila: Philiphines.

[3] Mitsubishi Heavy Industries. (1999). Instruction Book For Main Propulsion Unit. Nagasaki.

[4] Moore, W. (1985). De Stoomturbine (Turbin Uap). (S. Harsono, Trans). Jakarta: Bina Samudera.

[5] Raats, A.J. \& De Haan, P.C. (1985). Pesawat - Pesawat Uap (English). (Sutan Takdir

[6] Shlyakhin, P. (1993). Steam Turbines (Turbin Uap). Zulkifli Harahap (Trans). Jakarta: Erlangga.

[7] Waskito, Agus H. (2003). Turbin Uap. Semarang: Politeknik Ilmu Pelayaran.

[8] Wiranto, Arismunandar. (2004). Penggerak Mula Turbin. Bandung: ITB. 